Editorial

\title{
Open Access Publishing
}

Amelia Hadfield ${ }^{1}$ and Andrej J. Zwitter ${ }^{2}$

${ }^{1}$ Institute for European Studies, Vrije Universiteit Brussels, Pleinlaan 5, 1050 Brussels, Belgium;

E-Mail: amelia.hadfield@vub.ac.be

${ }^{2}$ Faculty of Law, University of Groningen, Oude Kijk in 't Jatstraat 26, 9712 EK Groningen, The Netherlands;

E-Mail: a.zwitter@rug.nl

\section{How to Cite this Article}

Hadfield, A., \& Zwitter, A. J. (2013). Open Access Publishing. Politics and Governance, 1(2), 102-103.

\section{Acknowledgement}

This Editorial was published by Librello, Politics and Governance's former publisher.

\section{About the Journal}

Politics and Governance is an innovative new offering to the world of online publishing in the Political Sciences. An internationally peer-reviewed open access journal, Politics and Governance publishes significant, cutting-edge and multidisciplinary research drawn from all areas of Political Science.

www.cogitatiopress.com/politicsandgovernance

\section{Editors-in-Chief}

Professor Andrej J. Zwitter, Faculty of Law, University of Groningen, The Netherlands

Professor Amelia Hadfield, Department of Psychology, Politics and Sociology, Canterbury Christ Church University, UK

\section{Managing Editor}

Mr. António Vieira, Politics and Governance, Cogitatio Press, Portugal 


\title{
Editorial
}

\section{Open Access Publishing}

\author{
Amelia Hadfield ${ }^{1, *}$ and Andrej J. Zwitter ${ }^{2, *}$ \\ ${ }^{1}$ Institute for European Studies, Vrije Universiteit Brussels, Pleinlaan 5, 1050 Brussels, Belgium; \\ E-Mail: amelia.hadfield@vub.ac.be \\ ${ }^{2}$ Faculty of Law, University of Groningen, Oude Kijk in 't Jatstraat 26, 9712 EK Groningen, The Netherlands; \\ E-Mail: a.zwitter@rug.nl \\ * Corresponding authors
}

Submitted: 7 July 2013 | Published: 10 July 2013

The rise of open source online journals, free online courses, and other changes in the research and education environment, coined the "academic spring" by some commentators [1], represents an increasing trend in opening up the rules of access for research. Universities, libraries, publishers and even governments are paying attention to this new movement often referred to with the acronym A2K (access to knowledge).

Peter Suber, the director of the Harvard Open Access Project defines open-access (OA) literature as "digital, online, free of charge, and free of most copyright and licensing restrictions" [2]. When reading the overview that Suber presents of the new domain of open-access literature, it is clear that there are common viewpoints from both sides of the Atlantic on the benefits of offering a place online for royalty-free research. Groups supporting open access research range from Bethesda, Maryland to Berlin, Germany.

In the UK, a report commissioned by the government indicated that universities in the country are paying over 200 million pounds per year for access to scientific journals [1]. In fact, the price of access for journals has risen four times as fast as inflations since the 1980s [2]. The UK government has shown great interest in developing a new model for open access journals and cited the importance of developing an American-European partnership in order to bring costs down and effectively make the transition to open access research [1].

Similarly, the Dutch Government has developed policies and makes available funds to support open source initiatives [3]. One of the main reasons cited for this transition is the increasing belief that the public should have the right to access publically funded research. The European Union follows a similar route. For the first time, the European Union introduced a reimbursement system for the costs of open source publications produced in FP7 projects. This policy will be carried through to Horizon 2020 [4].

Of course, concerns remain over the quality of research if open access prevails. But the status of being an open access journal does not preclude peer review, and Suber argues that the exact same standards of peer review of published works can be, and are already, conducted for open source journals. Peer review also does not depend on the cost or the medium of a specific journal, and can be applied for open access journals as well [2].

$\mathrm{OA}$ is also deemed to be more cost-effective than the traditional journal literature. The Harvard Open Access Project reports that OA eliminates all parts of subscription management, removes printing costs, puts an end to the need for legal fees and does not require the same type of marketing approach as traditional subscription journals. OA generally tends to monetize by requiring authors to pay a one-time fee to the open source journal [2]. However, this is only one type of business model for $O A$ journals among a variety (e.g. Green OA self-archiving or Gold OA publishing).

OA also does not dampen the motivation of authors to publish their work. In fact, it is easier for $O A$ journals to allow the author to retain copyright than in traditional journals [2]. Authors that choose to publish 
in OA sources allow their work to be read, distributed and reviewed by a wider audience than in traditional journals, which are only available to paying subscribers. In many ways, OA benefits the author themselves by increasing their profile and the visibility of their work, and the audience as they benefit from having access to the research they are interested in.

$\mathrm{OA}$ allows for a lessening of the divide between rich and poor in terms of access to research material. Citizens that cannot enroll in universities or in research institutions have the ability to access previously denied research. In a time where budgets are increasingly being cut, readers and general citizens do not have to rely solely on the budgets of their local or university libraries to obtain the research they need. Universities can benefit by more greatly distributing the work of their researchers and reduces the cost of journal subscriptions allowing that to be allocated for something else. Funding agencies and governments benefit by having research disseminated more widely, ultimately allowing it to be more useful in the long-term [2].

Advancing a policy of open source research has also a wider, border-crossing effect that aims to address global challenges and to maximize the social and economic benefits of research, as the G8 Science Ministers acknowledged on the 12th of June 2013 [5]. While the G8 Science Ministers agreed that global challenges require a strengthening of a global re-

\section{References}

1. Alok J. Open Access Is the Future of Academic Publishing, Says Finch Report. The Guardian. 19 June 2012. Available from: http://www.guardian.co.uk/scie nce/2012/jun/19/open-access-academic-publishing-fin ch-report (accessed on 27 June 2013).

2. Suber P. Open Access Overview. 2 April 2013. Available from: http://legacy.earlham.edu/ peters/fos/ overview.htm (accessed on 27 June 2013).

3. Dutch National Website on Open Access to Scholarly Information. Available from: http://www.open access.nl (accessed on 28 June 2013). search infrastructure, they also recognized that the best way to achieve this would be opening up research data to accelerate discovery and innovation. Eventually, the open source publication of research findings is another important point identified by the G8 Science Ministers.

Ultimately, it seems that the transition is already occurring and that there is a co-existence between traditional, subscription-based journals and the build-up of open access journals. It also appears that there is a general agreement on the positive benefits of $\mathrm{OA}$ among many groups operating in both the US and the EU. An emerging concern in the contemporary politics of $\mathrm{OA}$ and something that might call for specific OArelated international regulations in the future is the protection of intellectual property rights [6]. Now it remains to be seen how long these trends will continue and how much further OA journals will develop. The inclination towards open access can only benefit the greater proportion of participants in society and can further revolutionize the movement towards making educational resources more accessible to everyone.

\section{Acknowledgments}

The authors would like to thank Elizabeth Eckert for providing research and insight into the area of open access publications.

4. European Commission. Policy Initiatives-Open Access. Research and Innovation. 14 November 2012. Available from: http://ec.europa.eu/research/sciencesociety/index.cfm?fuseaction $=$ public.topic\&id $=1294 \& \mathrm{l}$ ang $=1$ (accessed on 28 June 2013).

5. Foreign and Commonwealth Office. G8 Science Ministers Statement. 12 June 2013. Available from: https://www.gov.uk/government/news/g8-science-min isters-statement (accessed on 28 June 2013).

6. Kapczynski A. The Access to Knowledge Mobilization and the New Politics of Intellectual Property. Yale Law Journal. 2008;117(5):804-885. 